\title{
Energy Simulation and Materials Dynamic Characteristics of Combined Power Plant
}

\author{
Shao Meng-lin 1, a, Liang Qian-chao ${ }^{1, b}$, Zhan Hai-yang ${ }^{1, c}$, Zhang Tao ${ }^{2, d^{*}}$ \\ ${ }^{1}$ The College of Naval University of Engineering, Wuhan 430033, China \\ ${ }^{2}$ Huazhong University of Science and Technology Tongji Hospital, Wuhan 430033, China \\ ashao_430063@163.com, blqc163cc@163.com, 'ocean081552@163.com, \\ d13387508398@163.com
}

Keywords: Combined power plant, Simulation, Dynamic characteristics.

\begin{abstract}
Combined power plant has been the important development trend of ship power in the future. The dynamic characteristic of the power plant has made a great impact on stability, maneuverability and economy of the ship. So the research of dynamic Characteristic on the combined power plant has great significance to the usage and management of the combined power plant of our country. This paper has researched various types of combined power plant. After studying the switching and control Strategy of CODAD, the switching process should adopt the equal power switching method because of the characteristics of less time consuming and little fluctuation. By comparison the performances of the different operation modes, it is concluded that COGAG and CODOG has the better performances. With the development of the technology, COGAG and CODOG will become the main operation modes of ship power in the future. The conclusion will do good to the application of COGAG and CODOG.
\end{abstract}

\section{Introduction}

With the rapid development of computer technology, Computer simulation and optimization technology has been closely combined. The stability and dynamic performance of the propulsion control system are optimized by this way. Combined power plant has its unique advantages which is adopted on more and more warships. Combined power plant has a variety of forms. The CAGAG has its own unique advantages in several types of combined power plant. As the power unit of cruising and full speed is a gas turbine, CAGAG has a better flexibility than CODAG and CODAD, and it has a much smaller unit of weight. COGAG devices are commonly the same type of gas turbine. So it has the same type of fuel oil and lubricating oil, and the better maintainability. By this way, we can greatly save the cost of protection and maintenance, reduce the dependence on the logistics support system.

The propulsion system of the combined power plant adopts the single machine propulsion system at low speed, and use the twin-engine incorporation at a higher speed. So it must be related to the control problem of twin-engine incorporation. In order to maintain the stability of the speed and power allocation of the two main units during the conversion, the appropriate control strategies should be researched. Therefore, by analyzing the simulation results of the propulsion system, it has the important significance for two aspects. Firstly, the overall structure of the combined power plant, and the matching technology of the working condition can be obtained. Secondly, the key problem of twin-engine incorporation of combined power plant is the analysis of load distribution and transfer law. By studying it can do good to the application o the dynamic characteristics and control law of the parallel, disconnection, switch combined power plant.

\section{Research on Switching and Control Strategy of CODAD}

Characteristics of CODAD. CODAD is the abbreviation of combined diesel and diesel configuration. Fig. 1 is the structure of CODAD. Because of its characteristics and advantages, it has broad prospects for development. It is necessary to be made a systematic study, especially the dynamic characteristics of the system and the control strategy. 


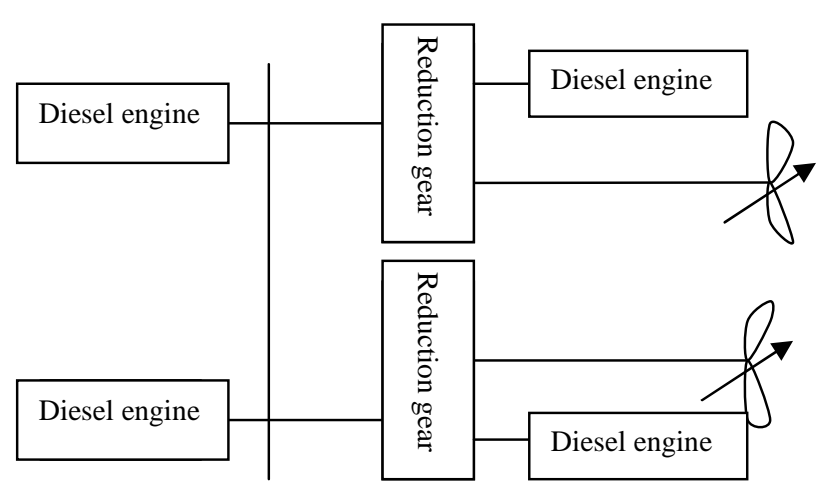

Fig. 1 Schematic diagram of CODAD.

Operating Conditions and Switching. The main operating conditions of switch are double operation to four double pulps and four operations to double pulps. The two cruise host is running when it is double operation double pulp. And then the other two hosts incorporate according to the rules of procedure and the operating condition become four operation double pulps. The four hosts are running when it is four operation double pulps. Two of the host according to the provisions of the program exit and the operating condition become double operation double pulp. Fig. 2 is the simulation curves for the single machine deceleration operation to the common run of the dual machine.

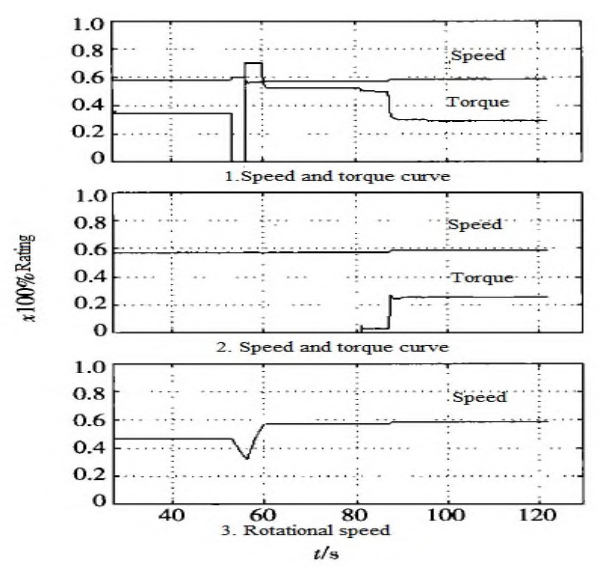

Fig. 2 Operating mode switching curve.

System Switching Control Strategy. According to the structure of gear box and the design of experiment scheme, this system should adopt the following strategies in the process of switching.

(1) When switching a single machine to double, the best way is to reduce the speed of the heavy load machine. At the rated speed of $60 \%$, and then under the same conditions, the two machine will be incorporated into the light load. In case of emergency, the light load machine can be incorporated at any speed. But when the clutch engagement, the two machine speed must be equal, or the speed of light load machine slightly larger than the heavy load machine, otherwise the clutch will be damaged.

(2) When you switch a double machine to single, the total load should be reduced to less than a single machine load under normal circumstances. For a variable pitch propeller, we can use the method of reduce the pitch. For fixed pitch propeller, we can reduce speed firstly, and then disengaged a clutch.

(3) Usually, considering that the total load of the vehicle is more than a single machine load, and the smoothness and accuracy of load transfer, we should avoid single overload, and ensure the load average distribution or the degree of imbalance within the limits of a certain expectation (for some 
special circumstances, such as after the overhaul). Otherwise, switch must be automatically carried out by the controller according to the setting program.

\section{Propulsion System of CODA (O) G.}

There are two main forms of CODA $(\mathrm{O}) \mathrm{G}$. One is CODOG, the other is CODAG. Focus discussion is CODOG.

Common Use Type Combined Power Plant CODAG System. The CODAG device is connected with a diesel engine and a gas turbine through a cross coupling gear box. The characteristic of Figure 3 is that the propeller is driven by diesel engine alone on cruise, the propeller is driven by a diesel engine and a gas turbine in a high speed. The CODAG has the advantages that the whole power of the power device can be played at the high speed, so that the ship can obtain a higher speed. We can choose a larger power diesel engine for the cruise, so that the ship has a higher cruising speed. At full speed, due to the diesel engine and gas turbine working at the same time, it can improve the economy. The operation modes of CODAG are: 1 diesel engine running alone; 2 diesel engine and gas turbine switching process; 3 gas turbine operation alone; 4 diesel and gas turbine working process. The 2 and 4 working process is the key of CODAG operation.

The following focuses are the various switching modes and performance of the alternative use of combined power unit (CODOG).

Alternative Use of Combined Power Unit (CODOG).

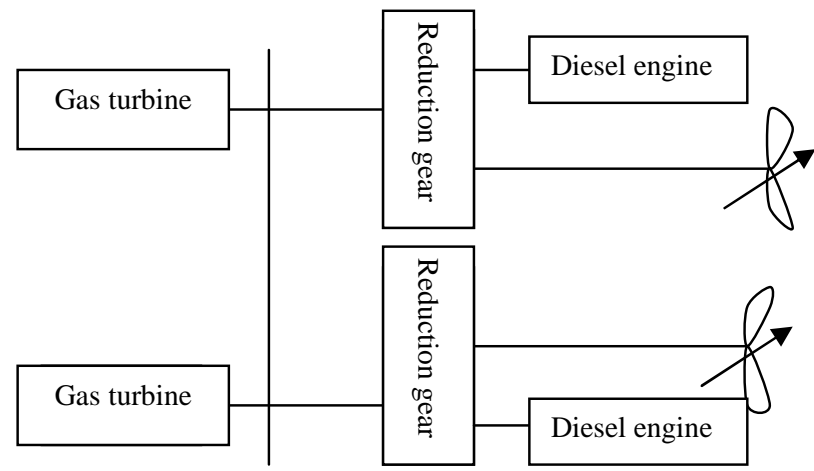

Fig. 3 Schematic diagram of CODOG.

The control strategies of system switching include: Analysis the characteristic of the switching process of the diesel engine to the gas turbine and the gas turbine to the diesel engine.

(1) Diesel engine switch to gas turbine

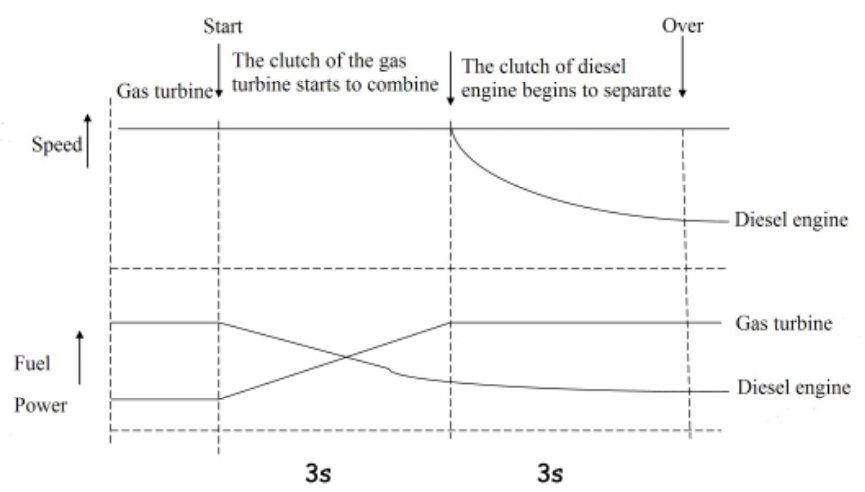

Fig. 4 The switching process of the diesel engine to the gas turbine.

From the image above, we know when the speed of gas turbine engine and diesel engine speed is the same, the gas turbine engine side SSS clutch starts to combine. After the gas turbine power began to increase, the diesel engine power began to decrease. After 3 seconds, diesel engine clutch 
start off. About 3 seconds, diesel engine clutch completely disengage. The entire switching process takes 6 seconds.

(2) Gas turbine switch to diesel engine

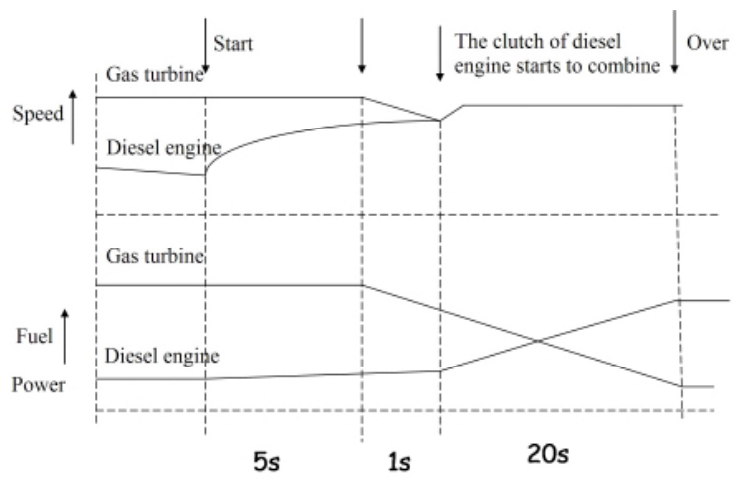

Fig. 5 The switching process of the gas turbine to the diesel engine.

From the image above, we know when the speed of the gas turbine is the same as that of the diesel engine, the coupling of the diesel engine hydraulic coupler is started. At the same time, the power of the diesel engine is rapidly increasing, the power of the gas turbine is rapidly declining, and the total power is basically unchanged. At 26 seconds, the gas turbine power is reduced to quit working, the diesel engine power to reach the maximum, bear all loads.

By comparing the above two switching process, we can see the diesel engine to the gas turbine switch process takes a very short time. It dues to the connection of gas turbine and gear box through the SSS clutch. SSS clutch has the characteristics of force transmission quickly, so gas turbine can quickly bear the load, and the diesel engine clutch is disengaged time-consuming short. Although the time consuming is very short, but in the process of combining the gas turbine is subjected to the impact of large. It is not conducive to the long-term reliable operation of the device.

\section{Propulsion System of COGA (O) G}

Combined power plant of COGA (O) $\mathrm{G}$ mainly has two forms. One is alternating use type combined power unit (COGOG), other is Common use type combined power unit (COGAG). The following focuses are the various switching modes and the performances of the common use type combined power unit (COGAG).

The Composition of COGAG. COGAG is made up of four identical gas turbines. Due to the gradual maturity of the cross connect technology, the kind of power device which is connected with the cross connect gear box is used more and more. Basing on demand we can choose one or more units to promote the two propeller forward. Generally, we do not choose three gas turbines work at the same time, except when a gas turbine is failure.

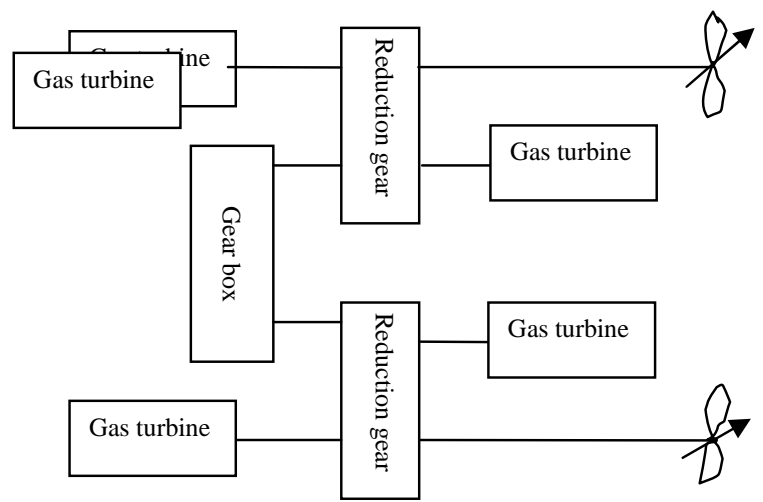

Fig. 6 Schematic diagram of COGAG system layout plan. 
Operation Mode of Common Use Type Combined Power Plant COGAG. COGAG main mode of operation between the conversion mainly has two ways, such as equal power and variable power. Regardless of the combination or separation, for COGAG, "equal power" switching has the characteristics of less time consuming, small fluctuation. So the switching process should adopt the "equal power" switching method. The operation mode of gas turbine combined power plant is more flexible. Such as the use of four same type of gas turbine to drive two propeller paddle propulsion scheme, the operation mode is that two sets of gas turbine drive a propeller through the gear box. Two sets of such devices are respectively installed on the left and right sides of the ship. They are connected through the gear box and make up the power allocation scheme of four gas turbine twin propeller. Economic speed or below, we can use single propeller or single gas turbine single propeller. Above economic speed, we use double gas turbine double propeller. We use four sets of gas turbine driving two propellers work together. COGAG power plant has no idle cruise gas turbine, which improves the operation efficiency of the propulsion system.

Single gas turbine two propeller switch to two gas turbine engine two propeller.

(1) Analysis of switching process of equal power

When the warship is to be realized by single gas turbine two propeller switch to two gas turbine engine two propeller, we should reduce the power of the original gas turbine, and increase the power of the gas turbine to be incorporated at the same time. When the power of the two gas turbine is equal, the cross connect process is completed, and the switch is completed.

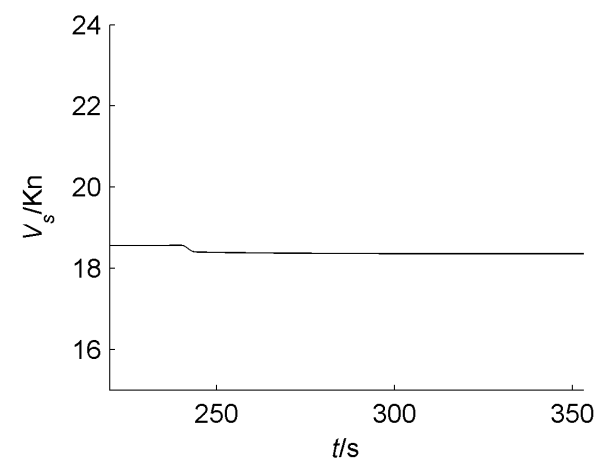

Fig. 7 Curve of ship speed change with time.

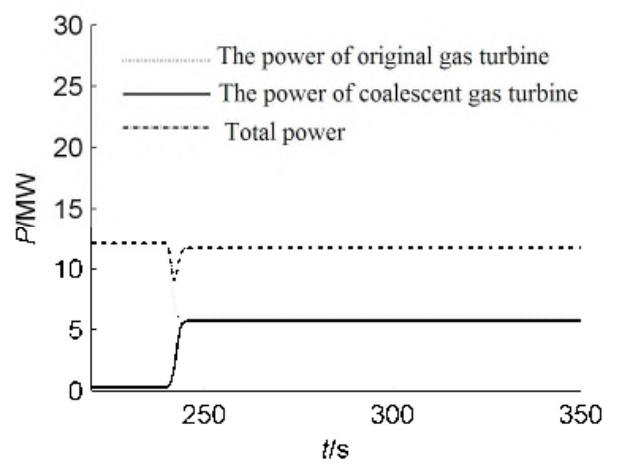

Fig. 9 Curve of gas turbine power over time.

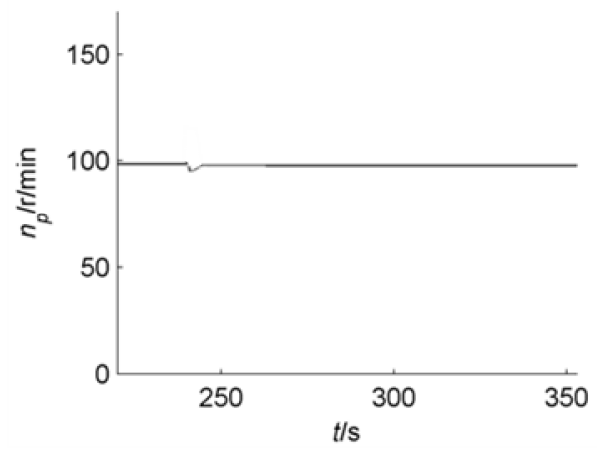

Fig. 8 Curve of propeller shaft speed change with time.

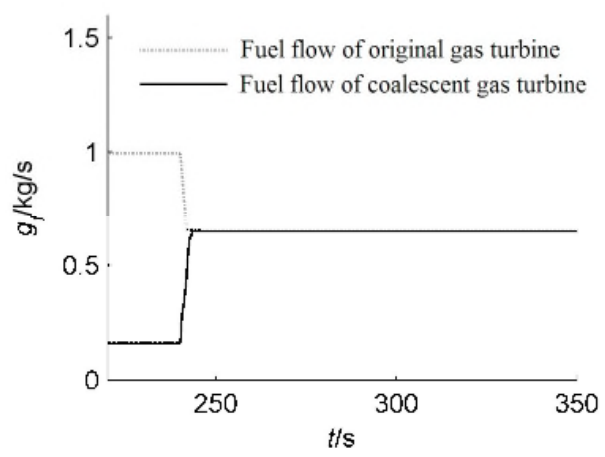

Fig. 10 Curve of fuel flow with time.

From the image above, when $t=240$ s, the gear box is connected. Power began to be transferred from the original the gas turbine through the cross gear box to be incorporated into the gear box of gas turbine. In 249s, the power of two gas turbines is equal and it completes the switch. The switching process takes 9 seconds. From the image above, the switching process is relatively stable, and the speed is basically unchanged. Such switching has great benefits for the stable operation of the gas turbine, which is beneficial to the long-term reliable operation of the gas turbine.

(2) Analysis of switching process of variable power.

When single gas turbine two propellers are working, the speed is 18.4 knots. In the process of 
power switching, the gas turbine power remains unchanged, and the power of gas turbine to be incorporated increase. When the power of gas turbine is equal, the switch is completed.

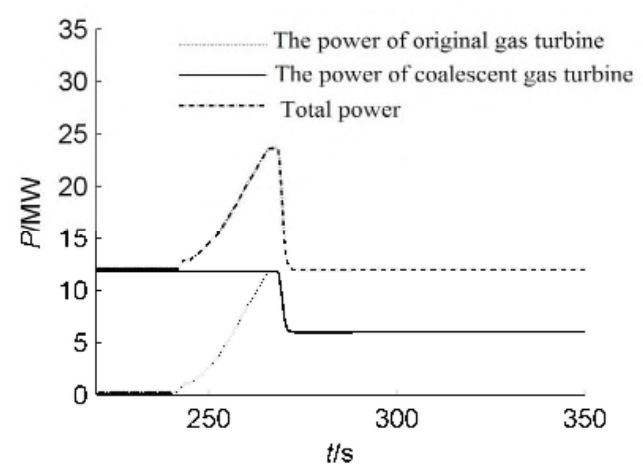

Fig. 11 Curve of gas turbine power over time.

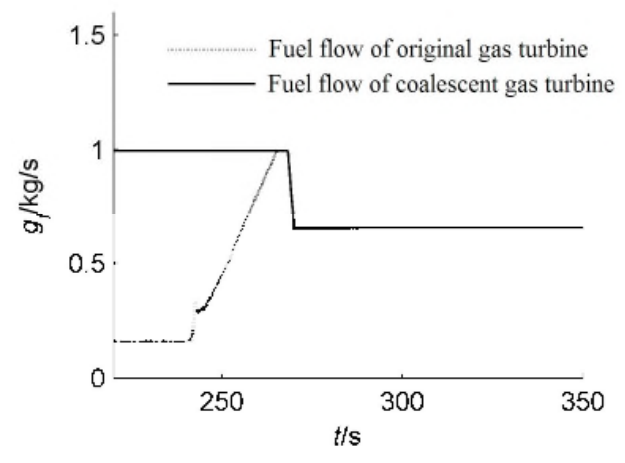

Fig. 12 Curve of fuel flow with time.

From the image above, gas turbine power remains unchanged at 240 seconds, we can increase the power of another gas turbine. The power of the two gas turbines is equal at 270 seconds. Then it complete separation. Switch is completed, and it takes 30s. As the power increases in the process of variable power, so the ship's speed began to increase. Then the power is reduced to the power of the original single machine, the speed of the ship and the propeller shaft gradually tend to be stable.

By comparing the two types of ship propulsion mode conversion, we know equal power take less time than variable power. And the speed is changed in the process of variable power, it is not conducive to the formation of the ship in the same speed. In addition, the propeller shaft speed also has a greater fluctuation. It has a negative impact on the reliability of power plants. However, compared with the method of equal power, the power of a gas turbine is only needed to be considered in the process of variable power. And the total power should be considered in the whole process, it is more difficult to achieve than variable power.

\section{Two gas turbine engine two propeller switch to single gas turbine two propeller.}

(1) Switching process of equal power analysis

In the steady state operation mode of two gas turbine engine two propeller switch to single gas turbine two propeller, which is mainly by regulating the fuel supply of two sets of gas turbine. The power of two gas turbines is reduced to a limited power range of one gas turbine engine. And then the power of the gas turbine reduces to be separated, and the power of the other gas turbine increases. Until the idle condition or out of work, the gas turbine is separated. The cross bonding process of connected gear box completes and the switching process completes. It takes $35 \mathrm{~s}$.

(2) Switching process of variable power analysis

Firstly, reduce the power of the two sets of gas turbines to a range of allowable. And then keep the power of one of the gas turbines unchanged, reduce the power of another gas turbine to be separated. In the process of cross connect, the power of the two gas turbine is gradually reduced. So the ship speed and shaft speed should be reduced to complete the switch. It takes $60 \mathrm{~s}$.

\section{Conclusion}

(1) Analyses of the working process and the various types of combined power plant have been made to achieve a switch between different modes.

(2) The COGAG is the main work mode of equal power and variable power. Whatever the combination or separation for COGAG, equal power switching has the characteristics of less time consuming and little fluctuation. So the switching process should adopt the equal power switching method. This paper provides a theoretical basis for the better operation of the ship.

(3) This paper has researched various types of combined power plant. By comparison, it is concluded that COGAG and CODOG has the better performances. Under the conditions of technical maturity, COGAG and CODOG will become the main operation modes in the future. 


\section{Reference}

[1] T. J. Ren, Q. C. Liang, Analyze the switching process of two working modes of COGAG, Ship Sci. Tech. (2013) 11.

[2] H. Y. Tang, S. Y. Li, Research on dynamic characteristics of COGAG and propeller matching, Harbin: Harbin Engineering University, 2010.

[3] G. Tian, X. L. Zhao, Reliability analysis of COGOG, Sci. Tech. 1998.

[4] P. B. Horacio, B. Todd, P. E. Henricks, A gas turbine dynamic model for simulation and control, ASME paper, 1998, 98-GT-78.

[5] M. Altosole, G. Benvenuto, M. Figari, Real-time simulation of a COGAG naval ship propulsion system, IMechE paper, 2009, 121, 47-61.

[6] P. L. Vassilios, P. K. Nicolaos, Modular Simulation of Marine Propulsion Systems Using an Engineering Building Block Approach, Sixth International Symposium on Marine Engineering (ISME), Tokyo 2000 - October 2. 